\title{
Effects of Hormone Treatments on Cut Flower Opening and Senescence in Wintersweet (Chimonanthus praecox)
}

\author{
Shunzhao Sui ${ }^{1}$, Jianghui Luo ${ }^{1}$, Daofeng Liu, Jing Ma, Weiting Men, \\ Lu Fan, Yu Bai, and Mingyang $\mathbf{L i}^{2}$ \\ Chongqing Engineering Research Center of Floriculture, Key Laboratory of \\ Horticulture Science for Southern Mountainous Regions, Ministry of Education, \\ College of Horticulture and Landscape Architecture, Southwest University, \\ Chongqing 400715, China
}

Additional index words. ethylene, abscisic acid, gibberellic acid, cytokinins, vase life, flower break strength, senescence-related gene

\begin{abstract}
Wintersweet (Chimonanthus praecox) is a woody garden plant with fragrant flowers, which blooms in deep winter. The vase life of fresh cut flowers is 8-9 days. We applied ethylene and 1-methylcyclopropene (1-MCP; an ethylene action inhibitor) to test the role of ethylene in flower opening and senescence. In addition, abscisic acid (ABA), gibberellic acid $\left(\mathrm{GA}_{3}\right)$, two cytokinins, 6-benzylaminopurine (6-BA), and zeatin (ZT) were also applied. The expression pattern of $C p S R G 1$, a senescence-related gene, was analyzed. Ethylene treatment accelerated flower opening and senescence, decreasing vase life by 2.1 days. It also decreased flower break strength, indicating the induction of abscission. 1-MCP slowed opening, delayed senescence, and prolonged vase life by 2.6 days. Ethylene dramatically induced the expression of the CpSRG1 gene, while 1-MCP suppressed it. ZT promoted flower opening and increased vase life by 1.6 days. It suppressed the expression of $C p S R G 1$. 6-BA, $\mathrm{GA}_{3}$, or $\mathrm{ABA}$ had no significant effect on flower opening and senescence of wintersweet.
\end{abstract}

Wintersweet (C. praecox) belongs to the Calycantaceae family and is a $2.5-$ to $3.0-\mathrm{m}$ tall deciduous shrub native to China. Wintersweet is a rare ornamental species and has over a thousand-year history of cultivation; as its name indicates, it blooms particularly in winter from late November to March in central, southern, and south-western China. Its unique flowering time and strong fragrance make it one of the most popular ornamental plants in China; it is appreciated as pot plants and cut flowers, and it has a high ornamental and economic value. The shrub has also been introduced into Korea, Japan, Europe, America, and Australia (Zhang and Liu, 1998). However, the vase life of cut wintersweet flowers is relatively short, and this has hindered the further expansion of commercial demand.

It is known that plant hormones are implicated in the regulation of flower senescence, and may have a dramatic effect on the vase life of cut flowers. Research studies have reported that ethylene promoted flower opening and senescence and shorted the vase life of flowers in a wide range of plant species; alternatively,

Received for publication 23 Apr. 2015. Accepted for publication 19 June 2015 .

This research was supported by the National Natural Science Foundation of China (grant no. 31370698), the Fundamental Research Funds for the Central Universities (XDJK2013A004, XDJK2010C071, and XDJK2015B013).

${ }^{1}$ These authors contributed equally to this article.

${ }^{2}$ Corresponding author. E-mail: limy@swu.edu.cn.
1-MCP has been used in prolonging cut flower vase life, and is now widely used commercially during transport (Scariot et al., 2014). Other plant hormones have also been studied, such as ABA, which is considered to be a natural promoter of flower senescence (Reid and Chen, 2007). $\mathrm{GA}_{3}$ has also been reported to delay wilting and senescence-associated proteolysis (Eason, 2002). Furthermore, it is known that $\mathrm{GA}_{3}$ acts as an antagonist to ABA or ethylene action, thereby delaying flower senescence (Hunter et al., 2004a, 2004b; Lü et al., 2014). It has also been noted that cytokinins delay petal senescence in both ethylene sensitive and insensitive flowers (Shimizu-Yumoto and Ichimura, 2013; Trivellini et al., 2015).

In general, flower senescence is associated with molecular changes in flower senescent organs (Tripathi and Tuteja, 2007). The senescence-related gene 1 (SRG1; encoding a novel member of the $\mathrm{Fe}$ (II)/ascorbate oxidase) is reported to increase in senescent organs of the model plant, Arabidopsis thaliana, hence, it was proposed as a marker for plant senescence (Baerenfaller et al., 2012; Callard et al., 1996; Heyndrickx and Vandepoele, 2012). For example, to evaluate the early stages of leaf senescence in the AtMYBL overexpressing line at the molecular level, the levels of $S R G 1$ were examined by quantitative polymerase chain reaction (qPCR). The transcripts of SRG1 accumulated to higher levels in AtMYBL overexpressing OX1-7 and OX8-6 lines than in wild type and atmybl RNAi ri6-6 and ri25-1 plants (Zhang et al., 2011).
In wintersweet, the role of exogenous ethylene in cut flower senescence is still unclear since conflicting results have been reported in the past (Ma et al., 2012; Sheng et al., 1999). The cytokinin 6-BA has been reported to be involved in the postharvest management of cut wintersweet flowers (Guo and $\mathrm{He}, 2004)$. Flower development in wintersweet is subject to complex regulation by multiple hormones as shown by transcriptomic data from the wintersweet flower using RNA-Seq (Liu et al., 2014). However, the involvement of hormones in the opening and the senescence of cut wintersweet flowers has not yet been investigated in detail.

Our previous research indicated that the expression level of CpSRG1 (SRG1) from wintersweet was significantly high during flower senescence, whereas it was very low at other stages of flower development. The results showed an association with flower senescence (Sui et al., 2012), so it provided us with a useful molecular tool with which to research the senescence of wintersweet.

Since a comprehensive analysis of the postharvest effects of plant hormones on cut wintersweet flowers has not yet been reported, we set out to investigate the effects of several hormones on postharvest quality. The applied hormones were ethylene, two cytokinins (ZT and 6-BA), $\mathrm{GA}_{3}$, and $\mathrm{ABA}$. To investigate the role of ethylene on senescence in cut wintersweet flowers, 1-MCP was also used. Furthermore, we detected the expression of the $C p S R G 1$ gene during the different hormone treatments. This work may contribute to find the effective hormone to delay wintersweet cut flowers senescence, which can be used in postharvest handling of cut flower.

\section{Material and Methods}

Plant material. Cut wintersweet, C. praecox cv. Concolor Makino (the local leading cultivar) was collected from an outdoor nursery in Jingguan, Chongqing, China. Wintersweet flower opening stages have been described previously (Sui et al., 2012; $\mathrm{Wu}$ and $\mathrm{Hu}, 1995)$ : stage 1, bud scales loosen; stage 2, flower buds turn green; stage 3 , flower buds enlarge and turn yellow; stage 4 , fragrance emerges; stage 5, flowers fully open with strong fragrance; stage 6 , petals begin withering. In this experiment, we added a stage 7 , the complete senescence period at which the petals turned brown, lost turgidity, and shriveled. Cut flowers were considered ornamentally unacceptable when they reached stage 7 .

Cut branches with $\approx 50 \%$ buds at stage 3 were harvested and transferred to the laboratory within $1 \mathrm{~h}$. Uniform diameters of 1-year branches with similar rates of buds or flowers were selected, cut to $\approx 30 \mathrm{~cm}$ in length, and rehydrated in distilled water for $1 \mathrm{~h}$. Each bud at stage 3 was labeled, treated, and observed. The experiments were conducted in a vase life evaluation room at $12 \pm 2{ }^{\circ} \mathrm{C}, 70 \%$ to $80 \%$ relative humidity, and $12-\mathrm{h}$ photoperiod (15 $\mu \mathrm{mol} \cdot \mathrm{m}^{-2} \cdot \mathrm{s}^{-1}$ irradiance) . 
Plant hormone treatments. Hormone concentrations were tested in preliminary experiments and the optimum concentrations were used in this study. The experiments were arranged into two groups. In one group, cut wintersweet flowers were treated with gaseous ethylene and 1-MCP.

In another group, cut flowers were placed in vase solutions containing different hormones.

Ethylene or 1-MCP treatment: cut flowers were placed in glass bottles with distilled water and sealed in gas-tight chambers for $24 \mathrm{~h}$. Solutions of $10 \mu \mathrm{L} \cdot \mathrm{L}^{-1}$ ethylene and $1 \mu \mathrm{L} \cdot \mathrm{L}^{-1}$ 1-MCP were chosen to treat the flowers. An open bottle containing $50 \mathrm{~mL} 1 \mathrm{~m} \mathrm{NaOH}$ was placed in the chamber to prevent the accumulation of $\mathrm{CO}_{2}$. Flowers of the control were placed in distilled water and sealed in the same size chambers with air. After 24-h treatments, all the flowers were placed in distilled water and then transferred to the evaluation room for further evaluation or experiments.

$\mathrm{ZT}, 6-\mathrm{BA}, \mathrm{GA}_{3}$, or ABA treatment: cut flowers were continuously held in glass bottles containing $200 \mu \mathrm{M} \mathrm{ZT}, 100 \mu \mathrm{M}$ 6-BA, $200 \mu \mathrm{M}$ $\mathrm{GA}_{3}$, or $100 \mu \mathrm{M} A B A$, respectively. Control flowers were placed in distilled water.

Phenotype observations. For each treatment, 45 flowers were used in duplicate. Each flower was defined as an independent sample. After treatment, 15 flowers were randomly chosen for morphological observation. The recording of flower stages was carried out daily based on visual symptoms, following the previously described standard. In addition, photodocumentation was made of the cut flowers. The vase life of each flower was considered as ended at stage 7 .

Recording of stamen movement was performed at 12-h intervals until the stamens were completely erect and enclosed the pistils. Measurement of flower diameter was conducted daily using vernier caliper based on the maximum width of each flower. Calculation of flower diameter increase rate (FDIR) was based on the following formula: FDIR $=\left(D_{\mathrm{n}}-D_{0}\right) \times 100 / D_{0}$ where $D_{\mathrm{n}}$ is flower diameter on the $\mathrm{Nth}$ day and $D_{0}$ indicates flower diameter before treatment.

Measurement of flower break strength. Flower break strength was measured in cut wintersweet flowers after $6 \mathrm{~d}$ of hormone treatment. The flower break strength was quantified using a Chatillon ${ }^{\circledR}$ DFS-010 force gauge (AMETEK Test \& Calibration Instruments, Hatfield, PA). For each sample, at least 15 flowers were measured. The flower break strength was recorded as the minimum force (in gram equivalents) needed to remove the flower from the stem (Sane et al., 2007).

$R N A$ extraction and real-time $q P C R$ analysis. For analysis of gene expression, whole flowers were collected at precisely 0 , $12,24,36,48$, and $72 \mathrm{~h}$ after hormone treatments, then immediately frozen in liquid nitrogen and stored at $-80{ }^{\circ} \mathrm{C}$. At each occasion, three flowers were collected as biological replicates.

Total RNA was extracted from flowers using an RNAprep pure Plant RNA Purification
Kit (Tiangen Biotech, Beijing, China) and reverse transcribed into cDNA using a PrimeScript RT Reagent Kit with gDNA Eraser (TaKaRa, Otsu, Japan). The genes for actin and tubulin were used for the calculation of relative transcript abundance. The primers used for real-time PCR (Supplemental Table 1) were designed by Primer Premier 5.0 (PREMIER Biosoft, Palo Alto, CA). A comparative $C_{\mathrm{t}}$ (threshold cycles) method of relative quantification was used to analyze the real-time quantitative reverse transcriptase PCR (qRT-PCR) data using Bio-Rad CFX Manager Software version 1.6 (Richmond, CA). All qPCRs for each experimental group used three biological replicates, with three technical replicates.

Data analysis. Statistical analyses were performed using SPSS version 16 software (SPSS Inc., Chicago, IL). Statistical differences among the data obtained from all treatments were determined using one-way analysis of variance followed by the Duncan's multiple range test at $P \leq 0.05$ or 0.01 .

\section{Results}

Effects of hormone treatment on vase life. To understand the detailed effect of hormones on the vase life of cut wintersweet flowers, we selected and labeled similar sized buds at stage 3 and treated them with different hormones.

As shown in Table 1, the total vase life of cut wintersweet flowers was $8.5 \mathrm{~d}$ for the control. After ethylene treatment for $24 \mathrm{~h}$, the total vase life was reduced to $6.4 \mathrm{~d}$, this was significantly shorter than the control. Alternately, 1-MCP significantly extended flower vase life to $11.1 \mathrm{~d}$. For the other hormone treatments: ABA treatment shortened the total vase life to $7.8 \mathrm{~d}$, but this was not significantly different from the control; ZT significantly extended flower vase life to $10.1 \mathrm{~d}$; and 6-BA and $\mathrm{GA}_{3}$ were less effective in extending vase life. Moreover, the different hormone treatments mainly affected vase life from stage 3 to stage 5, during flower bud to blooming.

Effects of hormone treatments on stamen closure and flower diameter. Hormone treatments had different effects on flower opening and senescence in cut wintersweet. As shown in Supplemental Fig. 1, ethylene treatment caused flowers to open and senesce quickly, and stamens to enclose much earlier than the control; after $1 \mathrm{~d}$ of ethylene treatment, the flowers almost reached stage 5 (bloom fully), and stamen closure took place at $1.1 \pm 0.2 \mathrm{~d}$,

Table 1. Effects of different hormones on vase life of cut wintersweet flowers (Chimonanthus praecox).

\begin{tabular}{llrr}
\hline & \multicolumn{3}{c}{ Vase life (days) } \\
\cline { 2 - 4 } Treatments & Stages 3-5 & Stages 5-7 & Total \\
\hline Control & $2.4 \pm 0.2 \mathrm{~cd}$ & $6.1 \pm 0.4 \mathrm{ab}$ & $8.5 \pm 0.4 \mathrm{~cd}$ \\
Eth & $1.5 \pm 0.2 \mathrm{e}$ & $4.9 \pm 0.2 \mathrm{c}$ & $6.4 \pm 0.3 \mathrm{e}$ \\
$1-M C P$ & $4.3 \pm 0.2 \mathrm{a}$ & $6.8 \pm 0.3 \mathrm{a}$ & $11.1 \pm 0.3 \mathrm{a}$ \\
ZT & $3.4 \pm 0.2 \mathrm{~b}$ & $6.7 \pm 0.2 \mathrm{a}$ & $10.1 \pm 0.1 \mathrm{~b}$ \\
6-BA & $2.8 \pm 0.3 \mathrm{c}$ & $6.5 \pm 0.2 \mathrm{ab}$ & $9.3 \pm 0.3 \mathrm{c}$ \\
GA $_{3}$ & $2.5 \pm 0.2 \mathrm{c}$ & $6.3 \pm 0.2 \mathrm{ab}$ & $8.8 \pm 0.3 \mathrm{c}$ \\
ABA & $1.9 \pm 0.1 \mathrm{de}$ & $5.9 \pm 0.3 \mathrm{~b}$ & $7.8 \pm 0.3 \mathrm{~d}$ \\
\hline
\end{tabular}

Data shown are means \pm SE for $n=15$. ${ }^{\mathrm{a}-\mathrm{e}}$ Values within a column followed by different letters differ significantly by Duncan's multiple range test at the 0.05 level of significance. compared with the control stamens closing at reached stage 7 on day 6 , compared with the control, which was still at stage 6. By contrast, 1-MCP markedly delayed flower opening and inhibited full flower opening, causing flowers to stay partially open at stage 4 from day 4 until the day 11 when wilting was observed. Stamen movement was also inhibited, resulting in complete enclosure being extended to $5.6 \pm 0.4 \mathrm{~d}$ (Fig. 1). For the other hormone, ABA treatment also accelerated flower opening and senescence; the flowers reached stage 5 in almost $2 \mathrm{~d}$, with stamen enclosure occurring simultaneously. The effect of ABA treatment on flower opening and senescence was less pronounced compared with that of ethylene treatment. However, ZT delayed flower opening and stamen enclosure for $\approx 1 \mathrm{~d}$ compared with the control. 6-BA and $\mathrm{GA}_{3}$ showed less effect on flower opening and stamen enclosure.

In wintersweet, an increase in flower diameter was always caused by petal expansion during flower opening, which peaked once flowers were fully open. When the flower began to wilt, the diameter decreased slightly. As shown in Fig. 2A, FDIR for the control flowers peaked at day 5. FDIR in the ethylenetreated flowers increased more quickly than that of the control, and reached a peak on day 3. Moreover, FDIR in the ethylene-treated flowers remained significantly higher than that in the control during the initial $5 \mathrm{~d}$. By contrast, 1-MCP retarded flower opening and senescence and caused flowers to maintain a partially opened status with bright color until wilting. The FDIR of 1-MCP-treated flowers increased slowly to a maximum on day 7 and remained lower than that of the control. For the other hormone, ABA treatment accelerated flower opening and senescence slightly. FDIR increased to a maximum on day 4 ; this was earlier than the control. ZT prolonged the partially opened period, showing an FDIR peak one day later than the control. 6-BA or $\mathrm{GA}_{3}$ slightly extended flower opening and senescence and resulted in a similar FDIR change to the control (Fig. 2B).

Effects of hormone treatments on flower break strength. Our preliminary experiment revealed that cut wintersweet flowers tend to abscise at initiation of senescence. To understand the effect of hormone treatment on cut flower senescence and abscission, flower break strength was measured as described in Material and Methods. As shown in Fig. 3, ethylene treatment significantly decreased $3.0 \pm 0.3 \mathrm{~d}$ (Fig. 1). Ethylene-treated flowers 


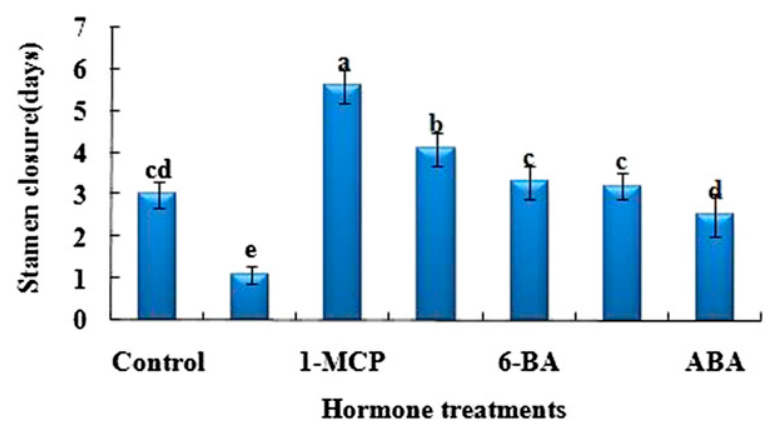

Fig. 1. Effects of different hormones on stamen enclosure in cut wintersweet flowers (Chimonanthus praecox). The values are the average days of stamen enclosure. Columns and bars represent the means and SE $(n=15)$, respectively. ${ }^{a-e}$ Different letters indicate significant differences among treatments by Duncan's multiple range test at the 0.05 level of significance.
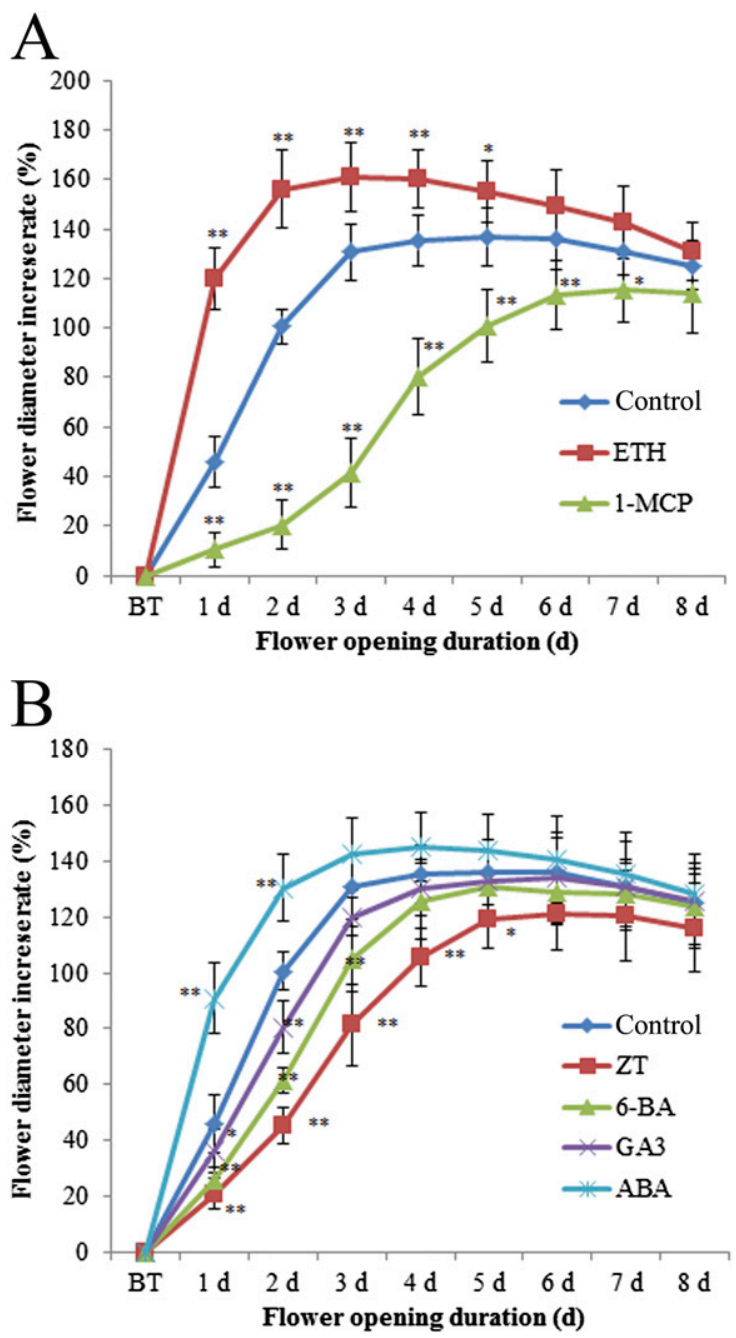

Fig. 2. Effects of different hormones on flower diameter increase rate (FDIR) change in cut wintersweet flowers (Chimonanthus praecox). The flowers were treated with gaseous ETH and 1-MCP (A) and placed in vase solutions containing $\mathrm{ABA}, \mathrm{GA}_{3}, 6-\mathrm{BA}$ and $\mathrm{ZT}(\mathbf{B})$, respectively. FDIR was based on the formula: FDIR $=\left(D_{\mathrm{n}}-D_{0}\right) \times 100 / D_{0}$, where $D_{\mathrm{n}}$ is flower diameter on the Nth day and $D_{0}$ indicates flower diameter before treatment. * $* *$ Significant difference from the control by Duncan's multiple range test at the 0.05 and 0.01 level of significance, respectively. Vertical bars represent the SE $(n=15)$.

flower break strength, while 1-MCP markedly increased it. In comparison with the control (3.19 \pm 0.38 gm equivalent), a 4 -fold decrease in break strength was observed in ethylene-treated flowers $(0.75 \pm 0.22 \mathrm{gm}$ equivalent), whereas a $34 \%$ increase in break strength was observed in 1-MCP-treated flowers ( $4.28 \pm 0.34$ gm equivalent) for the same period. For the other hormones, the flowers of ABA and ZT treatments showed a $23 \%$ decrease and $11 \%$ increase in break strength, respectively, compared with the control, while 6-BA or $\mathrm{GA}_{3}$ treatment slightly increased flower break strength.

Expression pattern of CpSRG1 after hormone treatments. Our previous work revealed that the expression level of $C p S R G 1$ was obviously upregulated at the senescence stage in wintersweet flowers, suggesting a possible role in flower senescence. Here, we investigated the expression change of the $C p S R G 1$ gene after different hormone treatments. As expected, CpSRG1 expression was markedly induced by exogenous ethylene (Fig. 4A). The CpSRG1 mRNA level was observed to upregulate at $12 \mathrm{~h}$ after ethylene treatment, and a notable increase of more than 12-fold compared with the control was detected in $24 \mathrm{~h}$. On the contrary, CpSRG1 expression showed a clear decrease after 1-MCP treatment at the transcriptional level compared with the control; it particularly showed a significant reduction at $72 \mathrm{~h}$ after treatment.

For the other hormones, the expression of $C p S R G 1$ was induced in ABA treatment compared with the control. $\mathrm{ZT}, \mathrm{GA}_{3}$, and 6-BA treatment decreased the expression of CPSRG1 compared with the control. This showed that ZT treatment was more effective in decreasing the expression of $C p S R G 1$ than $\mathrm{GA}_{3}$ or 6-BA treatment in cut flowers (Fig. 4B).

\section{Discussion}

Hormones are involved in many different processes throughout plant life, including growth, development, and senescence (Davies, 2010). Several hormones such as ethylene, $\mathrm{ABA}$, and $\mathrm{GA}_{3}$ have been reported to play important roles in flower opening and senescence. The specific regulation of flower opening and senescence is a complex process; for example, exogenously applied ethylene and ABA have been shown to accelerate senescence, whereas cytokinins delay senescence (Trivellini et al., 2015).

Ethylene is one of the most important hormones, and it plays a major role in many flowers (such as roses, carnations, and orchids) in regulating flower opening, senescence, and abscission (Scariot et al., 2014). A burst of endogenously produced ethylene in such flowers initiates senescence and coordinates the expression of genes required for the process (Rogers, 2013; Shahri and Tahir, 2011). In wintersweet, however, previous research detected no obvious production of ethylene from the flowers during flower development (Sheng et al., 1999). On the other hand, it has been reported that ethephon treatment of wintersweet cut flowers can accelerate the process of flower opening (Ma et al., 2012). We previously measured ethylene production of wintersweet flowers at different stages. The results showed that a small amount of endogenous ethylene was produced, with a maximum amount at the full-bloom stage (Luo et al., 2015). In this experiment, we found that exogenous ethylene accelerated wintersweet flower opening and senescence, and significantly shortened the vase life by $2.1 \mathrm{~d}$ compared with the control (Table 1; Fig. 1). Flower diameter increased more quickly, reaching its peak $\approx 2 \mathrm{~d}$ earlier than the control. The results of stamen movement and flower break strength 


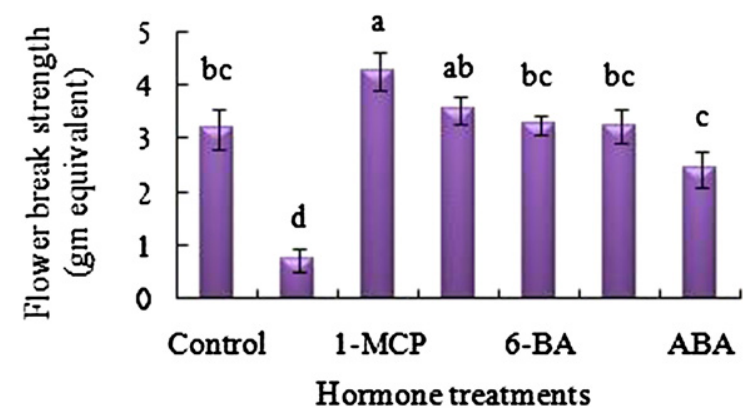

Fig. 3. Effects of different hormones on flower break strength in cut wintersweet flowers (Chimonanthus praecox). Columns and bars represent the means and $\mathrm{SE}(\mathrm{n}=15)$, respectively. ${ }^{\mathrm{a}-\mathrm{d}}$ Different letters indicate significant difference among treatments by Duncan's multiple range test at the 0.05 level of significance.
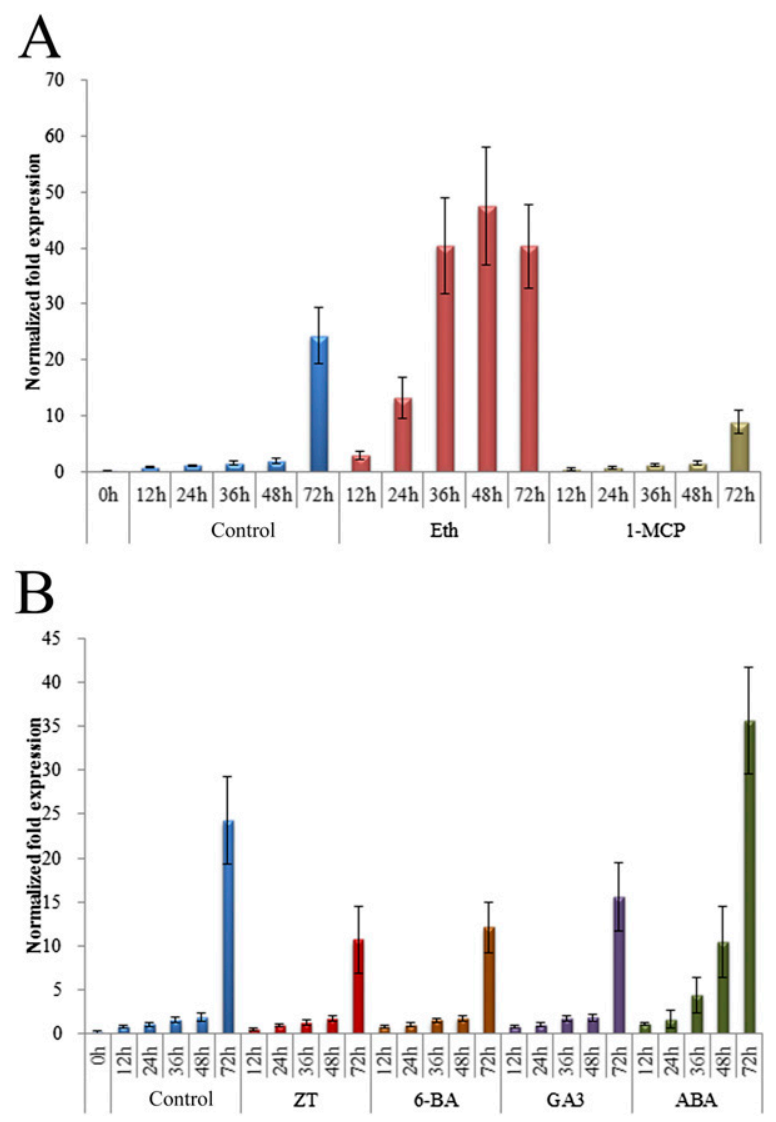

Fig. 4. Expression profiles of CpSRG1 mRNA in cut wintersweet flowers (Chimonanthus praecox) treated with different plant hormones. The flowers were treated with gaseous ETH and 1-MCP $(\mathbf{A})$ and placed in vase solutions containing $\mathrm{ABA}, \mathrm{GA}_{3}, 6$-BA and ZT (B), respectively. Data were normalized against a reference of wintersweet actin and tubulin genes. All quantitative polymer chain reactions (qPCRs) for each gene used three biological replicates, with three technical replicates per experiment; the error bars indicate SD.

also supported this point; the period of stamen enclosure was shortened by $\approx 2 \mathrm{~d}$ and a 4 -fold decrease in break strength was observed in cut flowers after ethylene treatment.

Another approach to confirm the effect of ethylene on wintersweet flowers is the application of 1-MCP, which binds to the ethylene receptor and regulates tissue responses to ethylene (Serek et al., 1995). The high efficacy of 1-MCP on improving vase life has been well documented in a range of ornamental species (Asil et al., 2013; Nergi and Ahmadi, 2014; Seglie et al., 2011; Shimizu-Yumoto and Ichimura, 2012). In this study, 1-MCP significantly delayed flower opening and extended flower vase life. Stamen movement was inhibited, resulting in complete enclosure at $2.6 \mathrm{~d}$ later than the control. A $34 \%$ increase in flower break strength was observed for the same period as the control. Together, our results suggest that cut wintersweet flowers were sensitive to exogenous ethylene treatment. This finding is in contrast to Sheng et al. (1999) who classified the wintersweet flower as ethylene insensitive. The apparent discrepancy may be explained by the method of ethylene treatment and the material selected. In our study, uniform flower buds at stage 3 were tagged and observed. The branches with the tagged buds were sealed and treated with $10 \mu \mathrm{L} \cdot \mathrm{L}^{-1}$ gaseous ethylene at $10^{\circ} \mathrm{C}$ for $24 \mathrm{~h}$. Whereas Sheng et al. treated cut wintersweet flowers with 50 or $200 \mathrm{mg} \cdot \mathrm{L}^{-1}$ ethephon (ETP) solution and recorded all the buds on the branches.

ABA is a natural regulator of flower senescence (Reid and Chen, 2007). Exogenous application of ABA has been shown to hasten flower senescence in certain flowers, such as daffodils (Narcissus pseudonarcissus) (Hunter et al., 2004a) and gladioli (Gladiolus grandiflora) (Kumar et al., 2014). In this study, continuous ABA treatment accelerated cut flower opening and shortened the vase life to some extent, but there was no significant difference when compared with the control. FDIR increased to a maximum one day earlier than the control. Stamen movement was slightly accelerated and flower break strength was decreased $(23 \%)$. In flowers where senescence does not respond to ethylene, ABA has been envisaged as the key factor regulating flower senescence (Kumar et al., 2014). Furthermore, ABA seems to be involved in the regulation of the senescence of ethylene-sensitive flowers. In roses and carnations, exogenously applied ABA modulates an early increase in ethylene production, enhancing the sensitivity to ethylene (Müller et al., 1999; Nukui et al., 2004). The complex relationship between ethylene, ABA, and senescence in species with ethylenesensitive floral senescence is therefore worthy of further investigation.

GAs are thought to be involved in flower opening (van Doorn et al., 2013b), and $\mathrm{GA}_{3}$ treatments increase the vase life of cut flowers such as carnations (Dianthus caryophyllus), Sandersonia aurantiaca, and daffodils (N. pseudonarcissus) (Eason, 2002; Hunter et al., 2004a; Saks and Van Staden, 1993). It has also been reported that treatment with $\mathrm{GA}_{3}$ mitigated the effects of exogenous ABA in some flowers (Hunter et al., 2004a, 2004b; Kumar et al., 2014). In this study, when wintersweet flowers were continuously held in solutions containing $100 \mu \mathrm{M} \mathrm{GA}_{3}$, postharvest characteristics were partially improved. However, when the data pertaining to quality was collected, the results were not significant.

Increasing cytokinin levels in plants is a strategy for delaying flower senescence (Trivellini et al., 2015). Researchers have showed that cytokinins are effective in extending the vase life of both ethylene sensitive and insensitive flowers, such as carnations (Taverner et al., 2000), petunias (Trivellini et al., 2015), iris (Macnish et al., 2010; van Doorn et al., 2013a), lilies (Arrom and Munné-Bosch, 2012). In cut wintersweet flowers, it has been reported that storage quality was improved and senescence was delayed when 6-BA was added to vase solutions (Guo and $\mathrm{He}$, 2004). In our research, ZT was more effective than 6-BA in extending vase life. ZT prolonged the partially opened period with a lower FDIR peak than that of 6-BA treatment or the control. ZT delayed flower opening and stamen enclosure for $\approx 1 \mathrm{~d}$ compared with the control. 6-BA had less effect on flower opening and stamen enclosure. 
The $S R G 1$ gene is reportedly expressed in senescing organs of the model $A$. thaliana plant and was thus proposed as a marker for plant senescence (Baerenfaller et al., 2012; Callard et al., 1996; Heyndrickx and Vandepoele, 2012; Zhang et al., 2011). In a recent study, we first isolated the $C p S R G 1$ gene from $C$. praecox flowers. Using qRT-PCR, we validated the transcript level of the CpSRG1 gene during blooming in wintersweet. The results showed that the expression of CpSRG1 was more than 10-fold higher in flowers at the senescent stage than at other stages. To clarify the efficiency of hormone treatment on the vase life of cut wintersweet flowers, the relative expression of the $S R G 1$ gene was examined in treated flowers. Our results showed that ethylene treatment dramatically induced the expression of CpSRG1 in cut wintersweet flowers, but treatment with 1-MCP greatly suppressed it (Fig. 4). Moreover, the level of CPSRG1 expression was partially induced by ABA application. However, the treatment of ZT, 6-BA, or $\mathrm{GA}_{3}$ showed an inhibitory effect on the expression of CPSRGI in cut flowers. The expression pattern of $C p S R G 1$ correlated well with the postharvest characteristics of cut wintersweet flowers after corresponding hormone treatments.

In summary, this study provided valuable insights into the role of exogenous hormones during cut wintersweet flower opening and senescence. Exogenous ethylene accelerated flower opening and senescence, however, the application of 1-MCP had a significant positive effect on flower longevity. Continuous treatments with $\mathrm{ABA}$ slightly shortened vase life. $\mathrm{GA}_{3}$, an $\mathrm{ABA}$ action antagonist, did not dramatically delay flower senescence. ZT notably increased vase life, showing a greater positive effect than 6-BA. We suggest further investigation to optimize the concentration and method to commercially use 1-MCP or $\mathrm{ZT}$ to extend the vase life of cut wintersweet flowers.

\section{Literature Cited}

Arrom, L. and S. Munné-Bosch. 2012. Sucrose accelerates flower opening and delays senescence through a hormonal effect in cut lily flowers. Plant Sci. 188:41-47.

Asil, M.H., M. Karimi, and H. Zakizadeh. 2013. 1-MCP improves the postharvest quality of cut spray carnation (Dianthus Caryophyllus L.) 'Optima' Flowers. Hort. Environ. Biotechnol. 54(1):58-62.

Baerenfaller, K., C. Massonnet, S. Walsh, S. Baginsky, P. Buhlmann, L. Hennig, M. Hirsch-Hoffmann, K.A. Howell, S. Kahlau, A. Radziejwoski, D. Russenberger, D. Rutishauser, I. Small, D. Stekhoven, R. Sulpice, J. Svozil, N. Wuyts, M. Stitt, P. Hilson, C. Granier, and W. Gruissem. 2012. Systems-based analysis of Arabidopsis leaf growth reveals adaptation to water deficit. Mol. Syst. Biol. 8:606.

Callard, D., M. Axelos, and L. Mazzolini. 1996. Novel molecular markers for late phases of the growth cycle of Arabidopsis thaliana cellsuspension cultures are expressed during organ senescence. Plant Physiol. 112:705-715.

Davies, P.J. 2010. The plant hormones: Their nature, occurrence, and functions, p. 1-15. Plant hormones. Springer, The Netherlands.
Eason, J.R. 2002. Sandersonia aurantiaca: An evaluation of postharvest pulsing solutions to maximise cut flower quality. N. Z. J. Crop Hort. Sci. 30:273-279.

Guo, W.M. and W.T. He. 2004. Effects of combined holding technology with ultrasonic wave on short time storage for cut wintersweet branch twigs. J. Beijing. For. Univ. 26:84-87.

Heyndrickx, K.S. and K. Vandepoele. 2012. Systematic identification of functional plant modules through the integration of complementary data sources. Plant Physiol. 159:884-901.

Hunter, D.A., A. Ferrante, P. Vernieri, and M.S. Reid. 2004a. Role of abscisic acid in perianth senescence of daffodil (Narcissus pseudonarcissus 'Dutch Master'). Physiol. Plant. 121:313-321.

Hunter, D.A., M.F. Yi, X.J. Xu, and M.S. Reid. $2004 \mathrm{~b}$. Role of ethylene in perianth senescence of daffodil (Narcissus pseudonarcissus L. 'Dutch Master'). Postharvest Biol. Technol. 32:269-280

Kumar, M., V.P. Singh, A. Arora, and N. Singh. 2014. The role of abscisic acid (ABA) in ethylene insensitive gladiolus (Gladiolus grandiflora Hort.) flower senescence. Acta Physiol. Plant. 36:151-159.

Liu, D.F., S.Z. Sui, J. Ma, Z.N. Li, Y.L. Guo, D.P. Luo, J.F. Yang, and M.Y. Li. 2014. Transcriptomic analysis of flower development in wintersweet (Chimonanthus praecox). PLoS One 9(1):e86976 doi: 10.1371/ journal.pone.0086976.

Lü, P.T., C.Q. Zhang, J.T. Liu, X.W. Liu, G.M. Jiang, X.Q. Jiang, M.A. Khan, L.S. Wang, B. Hong, and J.P. Gao. 2014. RhHB1 mediates the antagonism of gibberellins to $\mathrm{ABA}$ and ethylene during rose (Rosa hybrida) petal senescence. Plant J. 78:578-590.

Luo, J.H., J. Ma, D.F. Liu, J.F. Yang, W.T. Men, C. Wan, S.Z. Sui, and M.Y. Li. 2015. Effects of ethylene on cut flower opening and senescence and expression of ethylene receptor genes in wintersweet (Chimonanthus praecox). Plant Physiol. J. 51(2):253-258.

Ma, J., Z. Li, B. Wang, S.Z. Sui, and M.Y. Li. 2012. Cloning of an expansin gene from Chimonanthus praecox flowers and its expression in flowers treated with ethephon or 1-methylcyclopropene. HortScience 47:1472-1477.

Macnish, A.J., C.Z. Jiang, and M.S. Reid. 2010. Treatment with thidiazuron improves opening and vase life of iris flowers. Postharvest Biol. Technol. 56:77-84.

Müller, R., B.M. Stummann, A.S. Andersen, and M. Serek. 1999. Involvement of ABA in postharvest life of miniature potted roses. Plant Growth Regulat. 29:143-150.

Nergi, M.A.D. and N. Ahmadi. 2014. Effects of $1-\mathrm{MCP}$ and ethylene on postharvest quality and expression of senescence-associated genes in cut rose cv. Sparkle. Sci. Hort. 166:78-83.

Nukui, H., S. Kudo, A. Yamashita, and S. Satoh. 2004. Repressed ethylene production in the gynoecium of long-lasting flowers of the carnation 'White Candle': Role of the gynoecium in carnation flower senescence. J. Expt. Bot. 55:641-650.

Reid, M.S. and J.C. Chen. 2007. Flower senescence, p. 256-277. In: S. Gan (ed.). Senescence processes in plants. Blackwell, Oxford, UK.

Rogers, H.J. 2013. From models to ornamentals: How is flower senescence regulated? Plant Mol. Biol. 82:563-574.

Saks, Y. and J. Van Staden. 1993. Evidence for the involvement of gibberellins in developmental phenomena associated with carnation flower senescence. Plant Growth Regulat. 12:105-110.

Sane, A.P., S.K. Tripathi, and P. Nath. 2007. Petal abscission in rose (Rosa bourboniana var Gruss an Teplitz) is associated with the enhanced expression of an alpha expansin gene, RbEXPA1. Plant Sci. 172:481-487.

Scariot, V., R. Paradiso, H. Rogers, and S. De Pascale. 2014. Ethylene control in cut flowers: Classical and innovative approaches. Postharvest Biol. Technol. 97:83-92.

Seglie, L., K. Martina, M. Devecchi, C. Roggero, F. Trotta, and V. Scariot. 2011. The effects of $1-\mathrm{MCP}$ in cyclodextrin-based nanosponges to improve the vase life of Dianthus caryophyllus cut flowers. Postharvest Biol. Technol. 59:200-205.

Serek, M., E.C. Sisler, and M.S. Reid. 1995. Effects of 1-MCP on the vase life and ethylene response of cut flowers. Plant Growth Regulat. 16:93-97.

Shahri, W. and I. Tahir. 2011. Flower senescencestrategies and some associated events. Bot. Rev. 77:152-184.

Sheng, A.W., W.M. Guo, and Z.H. Sun. 1999 Study on dynamics of endogenous hormones and parameters concerned senescence in cut wintersweet flowers. J. Beijing For. Univ. 2:48-53.

Shimizu-Yumoto, H. and K. Ichimura. 2012. Effects of ethylene, pollination, and ethylene inhibitor treatments on flower senescence of gentians. Postharvest Biol. Technol. 63:111-115.

Shimizu-Yumoto, H. and K. Ichimura. 2013. Postharvest characteristics of cut dahlia flowers with a focus on ethylene and effectiveness of 6-benzylaminopurine treatments in extending vase life. Postharvest Biol. Technol. 86:479-486.

Sui, S.Z., J.H. Luo, J. Ma, Q.L. Zhu, X.H. Lei, and M.Y. Li. 2012. Generation and analysis of expressed sequence tags from Chimonanthus praecox (wintersweet) flowers for discovering stress-responsive and floral development-related genes. Comp. Funct. Genom. 2012:134596. doi: 10.1155/2012/134596.

Taverner, E.A., D.S. Letham, J. Wang, and E. Cornish. 2000. Inhibition of carnation petal inrolling by growth retardants and cytokinins. Aust. J. Plant Physiol. 27:357-362.

Tripathi, S.K. and N. Tuteja. 2007. Integrated signaling in flower senescence: An overview. Plant Signal. Behav. 2:437-445.

Trivellini, A., G. Cocetta, P. Vernieri, A. MensualiSodi, and A. Ferrante. 2015. Effect of cytokinins on delaying petunia flower senescence: A transcriptome study approach. Plant Mol. Biol. 87:169-180.

van Doorn, W.G., F.G. Celikel, C. Pak, and H. Harkema. 2013a. Delay of iris flower senescence by cytokinins and jasmonates. Physiol. Plant. 148:5-120.

van Doorn, W.G., I. Dole, F.G. Celikel, and H. Harkema. 2013b. Opening of iris flowers is regulated by endogenous auxins. J. Plant Physiol. 170:161-164.

Wu, C.L. and N.Z. Hu. 1995. Studies on the flower form and blooming characteristics of the wintersweet. Acta Hort. Sin. 22:277-282.

Zhang, R.H. and H.E. Liu. 1998. Wax shrubs in world (Calycanthaceae). China Science and Technology Press, Beijing, China.

Zhang, X., H.W. Ju, M.S. Chung, P. Huang, S.J. Ahn, and C.S. Kim. 2011. The R-R-type MYBlike transcription factor, $A t M Y B L$, is involved in promoting leaf senescence and modulates an abiotic stress response in Arabidopsis. Plant Cell Physiol. 52:138-148. 


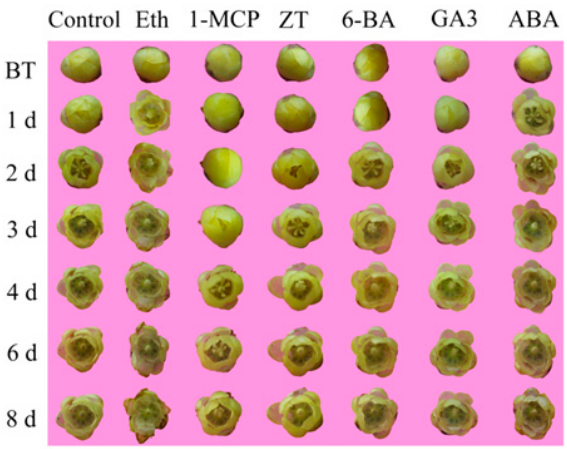

Supplemental Fig. 1. Effects of hormone treatments on flower opening and senescence in wintersweet (Chimonanthus praecox). Representative flowers before treatment (BT) and after 1, 2, 3, 4, 6, or $8 \mathrm{~d}$ of treatment are shown.

Supplemental Table 1. Primer sequences used for the quantitative reverse transcriptase polymerase chain reaction (RT-PCR) of the senescence-related gene in cut wintersweet (Chimonanthus praecox) flowers.

\begin{tabular}{lll}
\hline Gene name & Primer name & \multicolumn{1}{c}{ Primer sequence $\left(5^{\prime}-3^{\prime}\right)$} \\
\hline \multirow{2}{*}{ CpSRG1 } & CpSRG1-F & TAAGAACACCGTCCCATCTCGCTAC \\
& CpSRG1-R & GAGTGCAGTCTCTCCAATTCATCAG \\
Actin & Actin-F & AGGCTAAGATTCAAGACAAGG \\
& Actin-R & TTGGTCGCAGCTGATTGCTGTG \\
Tubulin & Tubulin-F & GTGCATCTCTATCCACATCG \\
\hline
\end{tabular}

